\title{
Coulisses
}

Revue de théâtre

13 | Hiver 1996

Varia

\section{Prix de la nouvelle étudiante, Vestiges d'elle}

Jean Robert Chauvin

\section{OpenEdition}

Journals

Édition électronique

URL : http://journals.openedition.org/coulisses/4393

DOI : $10.4000 /$ coulisses.4393

ISSN : 2546-9460

\section{Éditeur}

Presses universitaires de Franche-Comté

\section{Édition imprimée}

Date de publication : 1 janvier 1996

Pagination : 82-83

ISSN : 1150-594X

\section{Référence électronique}

Jean Robert Chauvin, «Prix de la nouvelle étudiante, Vestiges d'elle », Coulisses [En ligne], 13 | Hiver

1996, mis en ligne le 15 mars 2019, consulté le 03 octobre 2020. URL : http://journals.openedition.org/ coulisses/4393 ; DOI : https://doi.org/10.4000/coulisses.4393

Ce document a été généré automatiquement le 3 octobre 2020.

Coulisses 


\title{
Prix de la nouvelle étudiante, Vestiges d'elle
}

\author{
Jean Robert Chauvin
}

1 Je fus réveillé d'un rayon de soleil qui me caressait le visage en me frôlant les yeux. Le réveil avait encore dû s'épuiser à me sonner en vain avant de renoncer de lassitude. Pour se venger, il affichait insolemment neuf heures et quart. Même en sautant du lit, en me mettant à courir comme un fou, je serai en retard, alors autant traîner. Pour une fois prendre le temps.

Machinalement, par le poids d'une habitude dont je serai long à me défaire, ma main explora l'autre moitié du lit, vide, froide, lisse, propre. Seuls quelques cheveux enroulés sur l'oreiller, brillant dans le reflet du rayon de soleil qui m'avait tiré du sommeil, rappelaient sa présence à mes côtés, encore si proche. Il suffirait que je change les draps pour qu'ils disparaissent, et que s'évapore aussi son odeur, les effluves entêtants de son parfum, dans le sillage duquel elle m'avait si souvent entraîné, tel un automate qu'elle dirigeait, par lequel elle m'avait si souvent guidé tel un aveugle au regard tourné exclusivement vers elle.

Je m'assis sur le bord du lit, la tête entre les mains, les coudes sur les genoux, et contemplai tous les autres cheveux qui s'accrochaient à la moquette. Il faudrait sûrement passer l'aspirateur plusieurs fois pour que s'arrache le dernier et avec lui le dernier souvenir de sa tête renversée en arrière, de son rire à gorge déployée, de ses soupirs haletants, de ses cris de plainte implorée... À mon tour je secouai la tête pour la chasser de mes pensées.

Je me levai lentement, fragile comme un lendemain d'ivresse, et me dirigeai, lentement, vers la cuisine où je mis l'eau à chauffer pour un café. Le frigo était rempli de ses yaourts au bifidus, de ses boissons diététiques, de ses jus de fruits survitaminés, de son beurre sans cholestérol, de ses crèmes et ses fromages sans matière grasse, de ses légumes sans engrais, comme les étagères des placards craquaient sous le poids de toute sa nourriture allégée, sans colorant, sans conservateur, sans phosphate, sans spontanéité. J'attrapai un lot de sacs en plastique sous l'évier et entrepris de me débarrasser de tout ce superflu que je ne voulais plus voir, en essayant mentalement de dresser la liste de ce qu'il me faudrait racheter dès que possible au supermarché. À 
chaque fois qu'un sac était plein, je le nouai précautionneusement avant de le jeter dans la gueule grande ouverte du vide-ordures.

$\mathrm{Au}$ bout du sixième sac j'avais réussi à éliminer plus de la moitié de ces provisions de siège, mais je commençai à manquer de courage. L'eau bouillait sur le gaz. Je me préparai un café noir et brûlant, avec deux vrais sucres, et sortis de la cuisine, ma tasse à la main, une biscotte molle et margarinée dans l'autre. Il serait toujours temps, ce soir, demain ou un autre jour en rentrant du supermarché, de jeter le reste pour faire de la place, pour me donner de l'espace pour autre chose. Ce n'était pas si facile, ce ne serait pas si évident. Je savais que j'y arriverais. Je m'assis à la table basse de la salle et laissai errer mon regard autour de la pièce Partout, à chaque instant, dans chaque recoin, un détail me parlait d'elle, un souvenir jaillissait, un objet lui appartenant, quelque chose qui avait vécu par, avec, à travers elle. La reproduction d'un Matisse sur le mur, face à une photo de Doisneau, d'un baiser que nous avions reproduit inlassablement un dimanche de pluie désœuvré. Les coussins du canapé dont elle avait voulu que je choisisse les tissus avec elle. Le fauteuil en osier dans lequel elle se prélassait des éternités en regardant le vague, ses ongles peints ou la télévision. Audessus du magnétoscope les cassettes qu'elle enregistrait par douzaines pour les visionner en accéléré et en dessous de la chaîne la pile de ses $\mathrm{CD}$ dont elle n'écoutait de chacun qu'un titre, exceptionnellement deux. Sur l'étagère qu'elle avait pompeusement baptisée bibliothèque, parmi des romans policiers, sentimentaux, ou les deux à la fois, dont elle n'avait jamais achevé la lecture, les œuvres complètes d'un poète que je détestais sans avoir jamais osé lui avouer, et dont elle me lisait de longs passages, prenant mon absence pour de la concentration attentive. Le téléphone sur son guéridon, qui jamais ne sonnait pour moi et jamais ne sonnerait plus pour elle et pourrait ainsi se reposer des longues heures de confidence qu'elle lui avait infligé. Sur le coin de la table, un verre de whisky à moitié vide orné d'une trace de rouge à lèvre, et le même rouge sur les mégots débordant du cendrier. Encore quelques cheveux sur le tapis, encore quelques bribes de parfum...

Je savais qu'il faudrait du temps, encore bien des sacs et plusieurs cartons, des changements nombreux et radicaux dans le décor et les accessoires pour qu'elle achève de disparaitre, qu'elle cesse de m'obséder de son omniprésence, de me tourmenter de son souvenir lancinant. Cela aussi, je savais que j'y arriverais. Rien ne semblait impossible ni insurmontable. Je finis de boire mon café refroidi et retournai dans la chambre.

L'armoire était remplie de ses affaires, les cintres ployaient sous le poids de ses robes, ses jupes et de ses chemisiers, ses chaussures occupaient une pleine étagère. Les tiroirs de la commode débordaient de collants, de sous-vêtements de toutes les couleurs et de toutes les matières, tous plus affolants les uns que les autres. J'imaginai que le placard de l'entrée renfermait an moins une demi-douzaine de manteaux, vestes, capes, imperméables. J'essayai d'évaluer mentalement le nombre de valises nécessaire pour emballer toute cette garde-robe dont chaque frôlement, le moindre froissement, le plus imperceptible mouvement de l'air dans les tissus me chavirait dans une mémoire toute fraîche d'étreintes passionnées, de caresses soyeuses, de lents déshabillages, de désir impérieux, d'attirance irrésistible... Je me surpris, immobile au milieu de la chambre, un body de dentelle noire à la main, que je jetai à terre de colère. Ce n'était pas en donnant prise à la nostalgie que j'avancerai vers la paix. Je ne voulais pas rester immobile, inerte, imbécile Je fouillai rapidement dans le tiroir de mes propres affaires pour attraper une chemise, un slip et une paire de chaussettes propres et je battis en 
retraite vers la salle de bain.

Ce n'était pas un refuge! Les tablettes de l'armoire de toilettes croulaient sous les tubes de fards, les boites de poudre, les bâtons de rouge, les flacons de parfum. Des heures durant, cette salle de bain avait été son univers exclusif, que je partageais par ruse ou par aménagement subtil de mon emploi du temps, me levant avant elle ou allant me coucher après sa dernière séance de démaquillage, d'épilation, de masquage, de pommadage.

En plus de son parfum obsédant qui achevait de marquer son territoire, tout dans cette salle de bain lui appartenait, exceptés une brosse à dents élimée sur le lavabo, un peignoir râpé pendu au crochet de la porte, un rasoir et une bombe de mousse dans un recoin d'une étagère.

2 C'était cette portion de terrain, ce morceau de chez moi qu'il me serait le plus difficile de reconquérir. Il me faudrait encore plus de sacs qu'à la cuisine et davantage d'allerretours vers le vide-ordures pour rendre cet espace vierge et pouvoir envisager de me le réapproprier après libéré d'elle La place au-dessus du lavabo semblait encore, par ironie, renvoyer son image démêlant sa lourde chevelure au saut du lit, les yeux encore engourdis de sommeil et me criant de ne pas entrer pour ne pas la voir ainsi. Les murs résonnaient encore de l'éclat de son rire et de l'écho de ses cris [de] surprise ou de plaisir.

J'eus un instant la tentation de tout abandonner, de laisser tomber, de rapidement m'habiller et de fuir cet appartement, de déménager à l'autre bout de la ville, à l'autre bout du pays, de recommencer à zéro, de tout remettre à neuf, de repartir régénéré après avoir tout brûlé, de devenir amnésique et de laisser mon passé sur place sans plus me poser de questions, en refusant le tourment, les regrets, la moindre trace de nostalgie, faire une croix sur le passé, oublier jusqu'à son nom, jusqu'à son sourire, jusqu'à son parfum ...

Oui, je savais que je pourrais l'oublier et continuer à vivre. Ce n'était qu'une question de temps et de volonté. Je jetai un coup d'œil vers la baignoire: au fond, le seul véritable problème était de faire disparaître son corps...

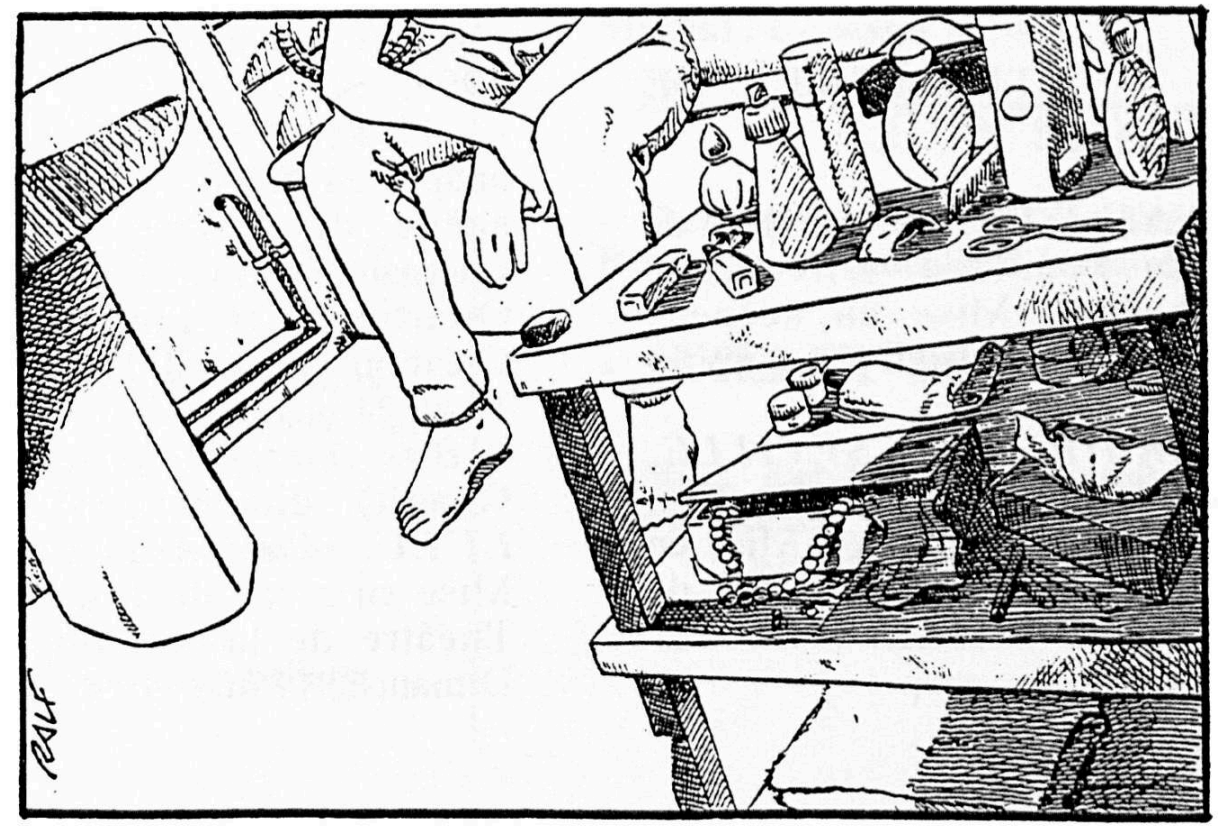




\section{AUTEUR}

JEAN ROBERT CHAUVIN

Prix d'encouragement du centre régional des Lettres 